\title{
Psychological Well-Being among Public and Private Undertakings in Aligarh
}

\author{
Saqib Bashir ${ }_{1}$, Prof. Abu SufiyanZilli 2
}

\section{ABSTRACT:}

The aim of this study was to compare the psychological well-being of public and private undertakings in Aligarh. The sample consisted of 100 participants including 50 each from public and private undertakings. Psychological well-being is a positive aspect that is present in every individual in varying degree $\&$ it is very important to measure psychological well-being among public \& private sector due to its role of productivity in each sector. Psychological well Being is an important aspect for effective performance in each undertaking sector, as it determines the internal feelings to persuade the external actions. Low psychological well-being is obvious to effect any domain of our life may it be academic or work life. 42 item versions Psychological well being scale by Carol ryff was used to collect the data from different private \& public undertakings in Aligarh. This scale consist of six dimensions namely Autonomy, Environmental Mastery, Personal Growth, Positive Relationship, Purpose in Life, Self-Acceptance. Mean, Standard Deviation and t-test were applied for analysis of data. The findings of this study revealed that over all psychological well-being of public undertakings is higher than private undertakings. Significant difference of overall psychological well-being was found between public and private undertakings in Aligarh .Furthermore, significant difference was found on all above mentioned dimensions of psychological well-being except autonomy and self-acceptance.

Keywords: Psychological well -being, public undertakings' and private undertakings'.

\section{INTRODUCTION:}

The public sector is the part of the economy concerned with providing various government services. The composition of the public sector varies by country, but in most countries the public sector includes such services as the military, police, public transit and care of public roads, public education, along with healthcare and those working for the government itself, such as elected officials(Barlow, J. Roerich, et;al 2010). Businesses and organizations that are not part of the public sector are part of the private sector. The private sector is composed of the business sector, which is intended to earn a profit for the owners of the enterprise, and the voluntary sector, which includes charitable organizations. The public sector might provide services that a non-payer cannot be excluded from (such as street lighting), services which benefit all of society rather than just the individual who uses the service. Different private sectors were found to be involved in more psychological well-being problems due to these changes. Both public \& private sector undertakings are found to differ in their structure \&organization, work schedules, work load, job security, salary, sense of stability in job\& organizational commitment which 
consequently affects their psychological Well-being at different level. Psychological wellbeing have started to receive impetus due to hectic work schedules \& changing technologies.

Psychological wellbeing is a positive aspect that is present in every individual in varying degree \& it is very important to measure psychological wellbeing among public \& private sector due to its role of productivity in each sector. Psychological well Being is an important aspect for effective performance in each undertaking sector, as it determines the internal feelings to persuade the external actions .Low psychological wellbeing is obvious to effect any domain of our life may it be academic or work life. Psychological wellbeing is associated with subjective feeling of contentment, happiness, joy ,satisfaction with self experience \& satisfaction with the world of work, sense of achievement \& belongingness\& no distress, dissatisfaction or worry etc.

The concept of well-being refers to fullest psychological functioning and experience. There is an increasing awareness that, positive affect is not the opposite of negative affect (Cacioppo \& Berntson, 1999), well-being is therefore not the absence of psychopathology or mental illness. The field of psychological well-being has witnessed the formation of two relatively distinct, yet overlapping, perspectives and paradigms for empirical inquiry on what is meant by well-being. The first that reflects the view that well-being consists of pleasure or happiness has been labelled hedonism (Kahneman ,Diener \& Schwarz, 1999). The hedonic viewpoint focuses on subjective well-being, which is frequently equated with happiness and is formally defined as more positive effect, less negative effect, and greater life satisfaction (Diener \& Lucas, 1999). In contrast, the second view lies in the actualization of human potentials. This view which reflects the fact that well-being consists of more than just happiness has been labeled eudemonism (Waterman, 1993), conveying the belief that well- being consists of fulfilling or realizing one's daemon or true nature. The eudemonic viewpoint focuses on psychological well-being, which is defined more broadly in terms of the fully functioning person and has been operational zed either as a Set of six dimensions (RYFF, 1989), as happiness plus meaningfulness (McGregor \& Little, 1998), or as a set of wellness variables such as self-actualization and vitality (Ryan \& Deci, 2000).

Components of psychological wellbeing include Autonomy, Environmental mastery, Personal, Purpose in life, Positive relations with other, Self-acceptance.

Autonomy: It includes determination of anything related to individual by himself, ability to carry out decisions by himself. Without any assistance by external people, and the activities may it be mental or physical are controlled by internal force.. Self-actualizers are described as showing autonomous functioning and resistance to enculturation. The fully functioning person is described as having an internal locus of evaluation, where one does not wish to seek approval from others but he finds him/her self-reliant to undertake activities related to any kind of work. Behaviour is judged by personal values, motivations

Environmental Mastery: It implies sufficient ability on the part of the individual required to control or manipulate complex environmental phenomenon. Here we are concerned with the environmental mastery related to work. It includes change of environment in a more rational way that is satisfying to individual himself $\&$ accepted in the environment as well. It includes ability to change the environment with the help of one's physical and mental activities to advance or to develop ones.. When ones gains adequate /sufficient knowledge skills, strategies to tackle wide 
range of environmental phenomenon in different contexts, He finds himself in a state of better psychological functioning.

Personal Growth: Full potential of psychological functioning requires not only that one achieve the fully functioning physical growth, but also that one continue to develop one's potential, to grow and expand as a person with the help of this physical \& mental growth. The need to actualize oneself and realize one's potential is central to development on personal growth. Personal development includes activities that improve awareness and identity, develop talents and potential, build human capital and facilitate employability, enhance quality of life and contribute to the realization of dreams and aspirations.

Personal growth includes development of characteristics that is widely appreciated \& accepted. It includes optimum utilization of personal resources in a way helpful to achieve one's aspiration and goals. No doubt, such person becomes role model for the other person as well. Personal growth includes individual who has got ability to express his internal feelings, intentions, and interests but maintains \& improves them also. The concept is not limited to self-help but includes formal and informal activities for developing others in roles such as teacher, guide, counselor, manager, life coach or mentor. When personal development takes place in the context of institutions, it refers to the methods, programs, tools, techniques, and assessment systems that support human development at the individual level in organizations. Personal growth is a very important complex phenomenon that everyone should attempt to inculcate \& it is important in every field of life .from the above it is concluded that personal growth is very important for psychological functioning.

Purpose in life: Every one of us has got some purpose in life that provides a sense of direction \& involvement in life. Purpose in life has a lot of small goals that one wishes to fulfill in an attempt to strive for the attainment of purpose one has in his life. Purpose in life varies from individual to individual \& this is of pivotal importance for effective functioning of psychological wellbeing. The definition of maturity also emphasizes clear comprehension of life's purpose goals in life, such as being productive and creative or achieving emotional integration in later life. Thus, one who functions positively has goals, intentions, and a sense of direction, all of which contribute to the feeling that life is meaningful.

Positive relations with others: This dimension emphasizes the importance of warm, trusting interpersonal relations. The ability to love is viewed as a central component of mental health. Self-actualizers are described as having strong feelings of empathy and effect on for all human beings and as being capable of greater love, deeper friendship, and more complete identification with others. Warm relating to others is posed as a criterion of maturity. Adult developmental stage theories also emphasize the achievement of close unions with others (intimacy) and the guidance and direction of others

Thus, the importance of positive relations with others is repeatedly stressed in conceptions of psychological well-being.

Self-Acceptance: This is defined as a central feature of mental health as well as characteristic of self-actualization optimal functioning, and maturity. Life span theories also emphasize acceptance of one's self and one's past life. Thus, holding positive attitudes toward oneself emerges as a central characteristic of positive psychological functioning. Self-acceptance is acceptance of self in spite of deficiencies. 
According to SHEPARD (1979), self-acceptance individual is well contented with himself ,values his ideas ,standards ,morale ,story of past ,has well acceptance for anything associated with his past ,present and is thought to be necessary for good mental health. Self-acceptance involves self-understanding, a realistic, subjective, awareness of one's strengths and weaknesses. It implies individual's acceptance of self for his strengths in comparisons to his weakness. It makes him to feel he is of "unique worth". \& has got something he is admired for. He develops certain positive \& negative points about himself always accepted, appreciated for among friends ,relatives \& people around him or her .This dimension is also important to contribute towards the development of psychological wellbeing\& mental health.

\section{OBJECTIVE OF THE STUDY}

- To study psychological wellbeing of employees in public Sector 'in relation to private sector undertakings'.

\section{HYPOTHESIS:}

Psychological wellbeing among public sector will be higher as compared to private sector undertakings' in Aligarh.

\section{METHOD}

\section{Participants:}

The participants included 100 in total selected randomly from different undertakings of public\& private sector. In addition to other undertakings, The private sector participants were selected from Narayana institutes ,Blue Dart, Private Banks located in centre point Aligarh \&companies located in Tala Nagri Ramghat Road Aligarh ,. Public sector includes university employees including post office, low profile employees of every kind, Departmental employees, provost office Indian Assurance Cooperative Limited (IACL) located in centre point etc. The complete sample was randomly selected \&almost education, gender, age was attempted to distribute equally from both the groups of participants.

\section{Tools used:}

Psychological well-being scale: Respondent rates themselves on each item according to a 6-point scale ranging from $1=$ strongly disagree to $6=$ strongly agree. Higher scores imply high psychological well-being. It consists of 6 distinct dimensions; autonomy, environmental mastery, positive relations with others, purpose in life, self-acceptance, and personal growth. The original scale developed by RYFF (1989) had 20 items contained within each of the 6 dimensions. This has been reduced to 7 items per dimension, and more recently 3 items per dimension. 7 items per dimension scale adapted by Carol Ryff (2000) is utilized for this study. There are three versions of the Ryff's scale, the parent scale is 20 -item version, the medium form is composed of nine $\& 7$ items, and the short form is composed of three items. The seven -item version for each dimension was used, which has a total of 42 items. Cronbach's alpha was .63 for autonomy, .53 for environmental mastery, .78 for positive relations with others, .73 for self-acceptance, .66 for personal growth, and .74 for purpose in life. Principal component analysis demonstrated one component for each dimension.

\section{Procedure:}

The data was collected from different public \& private undertakings using psychological wellbeing scale. The study was exhaustive one as data was collected from large area of ALIGARH 
including university campus .A large amount of convincing power helped to collect data from different employees of each undertaking sector. Each sector was motivated that their data will be used only for academic purpose \& will be kept confidential.

\section{RESULT}

Step wise discriminated analysis by using $t$-test for each dimension, $(\mathrm{N}=100, \mathrm{~PB}=50$ AND PVT=50 with $\mathrm{d} f \mathbf{f}=98$ )

\begin{tabular}{|c|c|c|c|c|c|}
\hline Dimensions & GROUP & $\mathrm{N}$ & Mean & (SD) & $\mathrm{t}$-value \\
\hline \multirow[t]{2}{*}{ Autonomy } & Public (PB) & 50 & 25.8 & 3.068 & \multirow[t]{2}{*}{1.6} \\
\hline & Private (PVT) & 50 & 24.5 & 4.85 & \\
\hline \multirow[b]{2}{*}{$\begin{array}{l}\text { Environmental } \\
\text { mastery. }\end{array}$} & Public (PB) & 50 & 30 & 3.528 & \multirow[b]{2}{*}{$5.34 * *$} \\
\hline & Private (PVT) & 50 & 25.3 & 5.132 & \\
\hline \multirow[b]{2}{*}{$\begin{array}{l}\text { Personal } \\
\text { growth. }\end{array}$} & Public (PB) & 50 & 30.9 & 4.249 & \multirow[b]{2}{*}{$4.81^{* *}$} \\
\hline & Private (PVT) & 50 & 27.1 & 3.655 & \\
\hline \multirow[b]{2}{*}{$\begin{array}{l}\text { Purpose in } \\
\text { life. }\end{array}$} & Public (PB) & 50 & 32.5 & 3.732 & \multirow[b]{2}{*}{$3.22 * *$} \\
\hline & Private (PVT) & 50 & 28.8 & 7.253 & \\
\hline \multirow[b]{2}{*}{$\begin{array}{l}\text { Positive } \\
\text { Relationship. } \\
\text {. }\end{array}$} & Public (PB) & 50 & 31.8 & 3.782 & \multirow[b]{2}{*}{$4.42 * *$} \\
\hline & Private (PVT) & 50 & 25.7 & 7.838 & \\
\hline Self-acceptance. & Public (PB) & 50 & 28.8 & 5.087 & \multirow[b]{2}{*}{0.98} \\
\hline Self-acceptance. & Private (PVT) & 50 & 27.9 & 4.001 & \\
\hline
\end{tabular}

\section{**Significant at 0.01 level}


Mean SD and t-value of employees of Public sector \& Private Sector undertakings' employees in Aligarh

\begin{tabular}{|l|l|l|l|l|}
\hline Group & N & Mean & SD & t-value \\
\hline $\begin{array}{l}\text { Public sector } \\
\text { undertakings' }\end{array}$ & 50 & 176.50 & 18.818 & $2.04^{*}$ \\
\hline $\begin{array}{l}\text { Private sector } \\
\text { undertakings' }\end{array}$ & 50 & 159.3 & 16.326 & \\
\hline
\end{tabular}

*significant at 0.05 level

From the result drawn by applying t-test on the sample of each 50 public \& private undertakings', it was found that overall psychological wellbeing of public sector is higher than private sector. Psychological wellbeing as expected was found to be higher in public undertakings'.\& on discriminative analysis for each dimension of psychological well-being, it was found that each dimension including, Environmental Mastery, Personal Growth, Purpose in life, Positive Relationship significant difference was found. The result for Autonomy and Selfacceptance was found to be insignificant for public \& private undertakings. More significant difference was found in Environmental Mastery followed by Personal Growth, Positive Relationship and Purpose in life.

\section{DISCUSSION}

Private undertakings' in Aligarh were found to be comparatively lower than public undertakings' in Environmental mastery that impacts employee morale, productivity and engagement - both positively and negatively. Relatively, Private sector was low in the area of environmental mastery, it includes change of environment in a more rational way that is satisfying to individual himself \& accepted in the environment as well. Employees in the public undertakings' sector thus have got more ability to change the environment with the help of their physical and mental activities in an attempt to advance or to develop oneself as compared to private undertakings of Aligarh. Relatively public undertakings has got adequate/sufficient knowledge skills, strategies to tackle wide range of environmental phenomenon in different contexts, employees in the public sector finds themselves in a state of better psychological functioning. Employees in the private undertakings experience difficulty managing their everyday affairs. Change or improve strongly their surrounding context; may be unaware of opportunities around them due to their busy \& distressing work schedules and may feel helpless in controlling their external world. Purpose in life for public \& private undertakings 'was found to lie in the high \& moderate level respectively. It means that public sector employees explained various purposes related to different domains of their life than private undertakings' in Aligarh. 
Self-acceptance ; it means acceptance for what one has got in his life it varies from individual to individual .in fact, everyone has got positive \& negative things associated with him\&selfacceptance individual has more satisfaction or happiness for whatsoever he has got in his life. He accepts his job, people around or near or dear one to him. He is satisfied for whatever he has achieved in his life .he is more satisfied for who he is. He loves his talents, skills, friends, job, physique etc. in a more desirable manner, thus has got more self-acceptance. Or According to SHEPARD (1979), self-acceptance is an individual's satisfaction or happiness with himself, and is thought to be necessary for smooth run of life. .Employees in either undertaking in Aligarh was found to be equal in their self-understanding, a realistic, awareness of one's strengths and weaknesses. Workers in both public \& private undertakings of Aligarh results in an individual's feeling about himself that he is of "unique worth" \& in this dimension of psychological wellbeing; it was found that neither of the two sectors differ significantly. Each undertaking of Aligarh accepts their self at their moderate level.

Each of the sectors in the dimension of autonomy provides insignificant result. They were nearly found equal at moderate level in Self-determination and independent; able to resist social pressures to think and act in certain ways; regulates behaviour from within; evaluates self by personal standards \& these attributes of psychological well-being are present in them only to a moderate level.

So far as personal Growth for each sector is concerned, it was found that each of the two differ significantly wherein public undertaking employees scored higher than private undertaking. It indicates that public employees in Aligarh undertake activities that are improving their Personal growth that includes development of characteristics that is widely appreciated \& accepted. It includes optimum utilization of personal resources in a way helpful to achieve one's aspiration and goals. No doubt, such person becomes role model for the other person as well. Personal growth includes individual who has got not only ability to express his internal feelings, intentions, and interests but maintains \& also improves them .public sector has got more awareness and identity, , build human capital and facilitate employability, enhance quality of life and contribute to the realization of dreams and aspirations.

Positive relationship with others was found higher in public sector employees than private employees with moderate level. The literature on motivational differences between private and public undertaking employees seems to accept that public sector employees are motivated by responsibility, growth, feedback or recognition and opportunities to the high levels of performance, more so than simply earning a good salary (Nell et al., 2001).

It is found that positive relationship with others is higher or strong in public sector undertakings' as compared to private undertakings'. It is found that their motivation \& responsibility for work schedules, work duration, produce sense of authority for their duties. Is evident from the collected data, employees in the public sector are positively related towards their family, relatives, friends. It is evident from the data that employees are sincere towards their relatives $\&$ it is important to keep in mind that approximately30\% public employees were within the university premises. Employees in the public sector have more stable job or secure career, low job stress, were more experienced and skilful towards their job, a public servant is given a sense of authority for his/her job with not too much interference or disturbance by others. In contrary to this, private sector employees are usually provided with salary not career, not job stability etc. 
It was also found that employees in the private undertakings in Aligarh city have low education level that further decreases their relative psychological wellbeing.

\section{SUGGESTIONS}

Psychological wellbeing of employees in undertakings of private sector is important for effective performance. Psychological wellbeing is mostly found to be affected by job insecurity \& in undertakings of private sector; lower psychological wellbeing is mostly due to job insecurity as is evident due to many studies. Burch ell (1994), on the assumption that job insecurity first of all reduces the psychological wellbeing examined the relationship of job insecurity \& psychological wellbeing among 600 bank employees in an individual \& found a lower level of psychological wellbeing among individuals who felt unsecure about their jobs.

Work performance may also affect psychological wellbeing of employees in different degrees at their respective public \& private sector. Comparative psychological wellbeing of private sector was found lower than public sector, it is found that mentoring is important for psychological wellbeing of undertakings in private sector. When young people join organization, may need guidance \& support from experienced people whom they may admire, can confide in \&receive advice from. Such a relationship is called mentoring. Mentoring affords an opportunity for an individual to share their concerns \& receive moral support\& guidance for their development. Mentoring begins when a trusting relationship is developed .Mentoring model behavioural norms for their protégés. They also learn to their personal \& job concerns. Help them search for solution to problems, share relevant experiences, respect to their emotional needs without making them dependant on the mentors \& cultivate long lasting yet informal personal relationship.

Managers \& supervisors need to explore \& investigate the problems of employees at their undertakings in Aligarh. He need to deal with the workers strength, weakness \& needs .Managers should attempt to make rationale use of workers strength ,to satisfy his needs .Career planning, succession planning, manpower planning, role clarity should be made by employees in each sector with adequate training.

In this regard, lab our welfare is an important step for the development of psychological wellbeing among private undertakings, giving feeling of satisfaction which even salary cannot. Lab our welfare should include added facility and amenities as added canteens, rest and recreation facility arrangements for travel to \& from work and for the accommodation of workers employed at a distance from their house .these and other services will facilitate the working condition of private employees working. When employees are provided with above mentioned benefits, it will inculcate in them intention or sense of loyalty towards their job \& organization. It will bring work motivation among workers, reduce absenteeism \& persuade them towards their jobs in a satisfied manner \& they will devote their time towards work as a result production will increase.

Furthermore, workers participation in management considered as a mechanism where workers have a say in the decision making process of an enterprises. Workers should have got suitable privilege for his contribution to industrial development. The experiments of BLAKE, MAYO, and LEWIN\& LIKERT popularized the belief that workers given participation in the 
management process is beneficial for effectiveness \& morale of any undertakings sector. It will ensure individual difference also. Person-focused intervention may also be implemented while keeping in consideration individual differences. For Person-focused intervention, coaching\& mentoring is important for development of psychological wellbeing .workers \& managers alike develop themselves by interacting with those they like for their job work they develop themselves by building a trusting relationship with people who nurture, support\& guide them.

In conclusion, it needs to be mentioned private undertakings in Aligarh has lower level of psychological wellbeing except autonomy \& self-acceptance in relation to public under takings. so important strategies should be further developed for development of psychological well-being at higher level.

\section{LIMITATION}

This study was carried out from Aligarh only with a small sample that consists of 100 in total with 50 from each public \& private organization.

\section{REFERENCES}

1. Barlow, J. Roehrich, J.K. and Wright, S. (2010).De facto privatization or a renewed role for the EU? Paying for Europe's healthcare infrastructure in a recession. Journal of the Royal Society of Medicine. 103:51-55

2. Burch ells, B. (1992). Towards a social psychology of the lab our market; or why we need to understand the lab our market before we can understand employment. Journal of occupational \& organizational psychology,65,345- 354

3. Cacioppo, J. T.\&Berntson, G.G.(1999).The affect system:Architecture and operating characteristics. Current Directions in Psychological Science. 8,133-

5. Diener, E. \& Lucas, R. E. (1999). Personality and subjective well-being. In Kahneman D, Diener E, Schwarz N, eds. Well-being: The Foundations of Hedonic Psychology. N

6. Kahneman, D., Diener, E., \& Schwarz, N. (eds.) (1999). Well-being: The foundations of hedonic psychology. New York: Russell Sage Foundations.

7. P.S., Gerber, P.D., Van Dyk, P.S., Haasbroek, G.D., Schultz, H.B., Sono, T., \& Werner, A. (2001). Human Resources Management. (5th Ed.). Oxford University Press, Cape Town.

8. Ryff, C. D. (1989). Happiness is everything, or is it? Explorations on the meaning of psychological well-being. Journal of Personality and Social Psychology. 57, 106981

9. Ramnarayan. S., Rao. T.V., Kuldeep Singh (1998).Organizational development (15 Ed.).Sage publications.

10. Ryan, R. M, \&Deci, E. L. (2000). Self-determination theory and the facilitation of intrinsic motivation, social development, and well-being. American Psychologist. 55, 6878.

11. Waterman, A. S. (1993). Two conceptions of happiness: contrasts of personal expressiveness (eudemonia) and hedonic enjoyment. Journal of Personality and Social Psychology. 64, 678-91 New York: Russell Sage Foundations pp. 213-29 